\title{
A COMPARISON BETWEEN ANALYTICAL AND NUMERICAL SOLUTION OF THE KROGH'S TISSUE CYLINDER MODEL FOR HUMAN BONE MARROW
}

\author{
M. A. Islam* \\ Department of Chemical Engineering and Applied Chemistry, \\ University of Toronto, 200 College Street, Toronto ON, M5S 3E5, Canada
}

\begin{abstract}
The Danish physiologist, August Krogh is the founder of the theory of oxygen transport to tissues. It was his famous tissue cylinder model developed for skeletal muscle, together with his colleague mathematician Erlang that laid down the foundation of the mathematical modeling of oxygen transport to tissues. Here an analytical solution of the Krogh's model has been presented based on justifiable assumptions in order to validate the numerical approach used to solve more realistic oxygen transport models. The numerical solution of Krogh's model is performed using computational fluid dynamics (CFD) software CFX 4.4. From the analytical solution, it is demonstrated that variation from the numerical result is less than $0.2 \%$ which in turn justifies the use of computer software in developing mathematical model for such physiological systems like BM.
\end{abstract}

\section{Introduction}

The mathematical modeling of oxygen transport processes in the human bone marrow (BM) is a very important arena of biological systems modeling that offers numerous clinical or medical applications. The $\mathrm{BM}$ is the sole site for effective hematopoiesis or blood cell production in the adult human being and oxygen is the principal nutrient for differentiation and proliferation of BM hematopoietic cells. So it is very important to have a better understanding of oxygen tension/concentration $\left(\mathrm{pO}_{2}\right)$ levels in the $\mathrm{BM}$.

At present, direct in vivo measurements of $\mathrm{pO}_{2}$ are practically impossible in BM and so, detailed modeling is the only available means to provide reasonable estimates. August Krogh's pioneering work of tissue cylinder model is the cornerstone of such mathematical modeling. Due to the physical inaccessibility of the $\mathrm{BM}$, no major study has been undertaken to-date that investigates the effect of oxygen and its distribution within the BM microenvironment. However, several sophisticated models have been developed for other tissues including the brain, muscle, skin and kidney. Although Krogh's model has been the starting point, in general, for all these models, in which the tissue is approximated as a cylinder with a single capillary at its centre, mathematical modeling of $\mathrm{pO}_{2}$ distribution in the human $\mathrm{BM}$ is very different and more challenging to that of other tissues due to the complexity of the vascular structure and the heterogeneity of the tissue region.

The use of numerical method necessitates the verification of the solution obtained and typically the

* Corresponding author's e-mail: ahsan.islam@utoronto.ca validation is via experimental results. However, as stated previously, the physical inaccessibility of the human bone marrow has hindered any detailed analysis through experimental methods. Using simplifying, but reasonable assumptions, an analytical solution to the oxygen transport model has been presented here. This in turn has been compared to the numerical solution obtained for the Kroghian model from the CFD software CFX 4.4. The geometry for the Kroghian system is presented in Figure 2, utilized to obtain a numerical solution.

\section{Krogh's Tissue Cylinder Model}

The foundation of the theory of "oxygen transport to tissue" was established by August Krogh, a Danish physiologist, who provided the first insights into the role of the smallest micro vessels in the supply of oxygen to striated or skeletal muscle. Together with his colleague, mathematician Erlang in 1918, Krogh developed the famous mathematical model named 'Krogh's cylinder model', which described how oxygen is delivered by a single capillary of a uniform array of capillaries to a surrounding tissue cylinder ${ }^{2}$. He theorized that the rate of transport is dependent upon the number and distribution of capillaries. In addition, he presumed that the capillaries are the sole supplier of oxygen to blood and each one obtained all of its oxygen by convection (bulk flow) from the terminal arterioles. Each capillary, in turn, served as an independent diffusive source delivering oxygen to a single distinct volume of tissue with homogenous oxygen consumption. Thus, Krogh's model predicted a linear decrease in hemoglobin oxygen content along each capillary ${ }^{3}$. The model also captures the 
longitudinal and radial $\mathrm{O}_{2}$ gradients within the capillary and surrounding tissue, further providing significant insights into the dynamics of oxygen delivery to the tissues ${ }^{2}$.

The essence of Krogh's model lies in the assumption that the tissue can be subdivide into circular cylindrical units, each of which has a capillary oriented along the axis and the units do not exchange oxygen with each other (Figure 1). In formulating this geometrical model, Krogh had in mind the capillary geometry in skeletal muscle where muscle fibers have a preferential direction and capillaries tend to be oriented along the fibers.

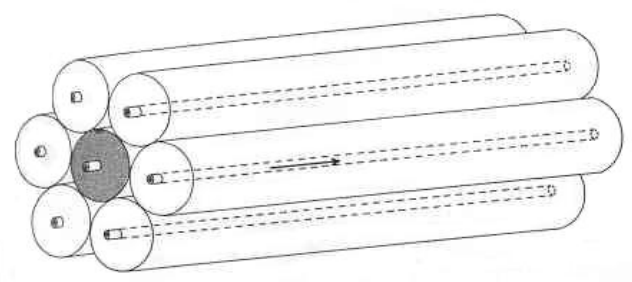

Fig 1. Geometry of the Krogh's tissue cylinder model $^{5}$.

The assumptions for formulating an equation governing tissue oxygen transport, are, 1) $\mathrm{pO}_{2}$ distribution in the tissue cylinder is axisymmetric, 2) the permeability of tissue to oxygen or the Krogh diffusion coefficient, $K=D_{t} \alpha_{t}$ is independent of spatial position; 3) $\mathrm{O}_{2}$ in the tissue is not bound to a carrier. Under these assumptions, the equation governing oxygen transport in the tissue can be written in the form $^{4}$

$$
\alpha_{t} \frac{\partial \mathrm{P}_{\mathrm{t}}}{\partial \mathrm{t}}=\mathrm{K}\left[\frac{1}{\mathrm{r}} \frac{\partial}{\partial \mathrm{r}} \mathrm{r} \frac{\partial \mathrm{P}_{\mathrm{t}}}{\partial \mathrm{r}}+\frac{\partial^{2} \mathrm{P}_{\mathrm{t}}}{\partial \mathrm{z}^{2}}\right]-\mathrm{M}
$$

At the outer boundary of the tissue cylinder the flux of oxygen is zero in accordance with the assumption that adjacent units do not exchange oxygen. Hence

$$
\frac{\partial \mathrm{P}_{\mathrm{t}}}{\partial \mathrm{r}}=0 \quad \text { at } \quad \mathrm{r}=\mathrm{R}
$$

Krogh further assumed that, 4) a steady state condition (the term $\partial \mathrm{P}_{\mathrm{t}} / \partial \mathrm{t}$ in equation 1 is zero), 5) a constant oxygen consumption rate, 6) negligible axial diffusion (the term $\partial^{2} \mathrm{P}_{\mathrm{t}} / \partial \mathrm{z}^{2}$ is small)

He did not consider the transport of oxygen in the capillary; rather the $\mathrm{pO}_{2}$ at the capillary wall was specified:

$$
\mathrm{P}_{\mathrm{t}}=\mathrm{P}_{\mathrm{w}} \quad \text { at } \quad \mathrm{r}=\mathrm{R}_{\mathrm{c}}
$$

The solution of equation 1 with boundary conditions 2 to 3 is

$$
\mathrm{P}_{\mathrm{t}}=\mathrm{P}_{\mathrm{w}}(\mathrm{z})+\frac{\mathrm{M}}{4 \mathrm{~K}}\left(\mathrm{r}^{2}-\mathrm{R}_{\mathrm{c}}{ }^{2}\right)-\frac{\mathrm{MR}^{2}}{2 \mathrm{~K}} \ln \frac{\mathrm{r}}{\mathrm{R}_{\mathrm{c}}}
$$

This equation gives the radial distribution of tissue $\mathrm{pO}_{2}$ in terms of capillary and tissue cylinder radii and tissue permeability. In particular, it permits the calculation of the minimum tissue $\mathrm{pO}_{2}$, which occurs at the outer rim of the tissue cylinder, i. e. at $\mathrm{r}=\mathrm{R}$.

\section{The Oxygen Transport Equation}

Substance diffusion is an equilibration process in which substance molecules are transferred from loci of higher concentration to ones of lower concentration and this is the basis of oxygen transport in blood. The basic law that is applicable in this study is Fick's second law of diffusion and the Henry-Dalton law, and its application yields the following equation:

$$
\alpha \frac{\partial p}{\partial t}=K \cdot \nabla^{2} p
$$

where $\alpha$ is the $\mathrm{O}_{2}$ solubility, $\partial \mathrm{p} / \partial \mathrm{t}$ is the change in $\mathrm{pO}_{2}$ with time and $\nabla^{2}$ is the Laplace operator.

In addition to the diffusion processes there are other mechanisms that exert their influence on the local oxygen distribution; these include ${ }^{1}$ :

1. Physiological oxygen sink; which may vary with local $\mathrm{pO}_{2}$ (michaelis-menten kinetics).

2. Presence of $\mathrm{O}_{2}$ carrier, hemoglobin $(\mathrm{Hb})$ implies the release or binding of oxygen.

3. This carrier bound $\mathrm{O}_{2}\left(\mathrm{Hb}-\mathrm{O}_{2}\right)$ represents a second oxygen species. The exchange between carrier-bound and free $\mathrm{O}_{2}$ is quantified via the release rate $\mathrm{R}$; which constitutes the link between these equations.

4. Facilitated diffusion enhances free $\mathrm{O}_{2}$ diffusive transport.

5. Local convection displaces free and $\mathrm{Hb}-\mathrm{O}_{2}$ at a rate depending on the velocity vector $(\mathbf{v})$. The change in local $\mathrm{O}_{2}$ and $\mathrm{Hb}-\mathrm{O}_{2}$ concentrations is proportional to the magnitudes of $\mathbf{v}$ and the concentration gradients.

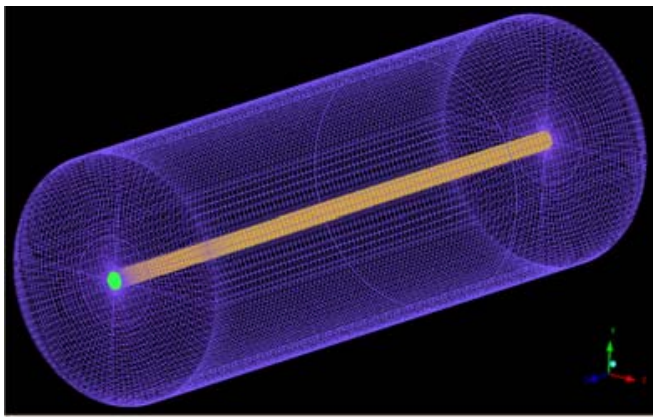

Fig 2. Krogh's tissue cylinder. 
Taking into account the above factors, the $\mathrm{O}_{2}$ transport equation can be written as ${ }^{1,4}$ :

$$
\begin{gathered}
\alpha_{b}\left[\frac{\partial p_{b}}{\partial t}+\vec{v} \cdot \nabla p_{b}\right]=\nabla \cdot\left[K_{b} \nabla p_{b}\right]-R \\
H_{T}\left[\frac{\partial \gamma}{\partial t}+\vec{v} \cdot \nabla \gamma\right]=\nabla \cdot\left[H_{T} D_{H} \nabla \gamma\right]+R
\end{gathered}
$$

where $\mathrm{R}$ represents the net rate of carrier $\mathrm{O}_{2}$ release. Under most conditions, it is further possible to reduce the above set of equations to form a single equation under the assumption that the reaction rate described is extremely fast and thus the two states are always in equilibrium. Accordingly, the hemoglobin saturation $(\gamma)$ solely depends on the partial pressure $\left(\mathrm{pO}_{2}\right)$. Thus equations 6 and 7 can be reduced to:

$$
\begin{aligned}
\alpha_{b}\left[\frac{\partial p_{b}}{\partial t}+\vec{v} \cdot \nabla p_{b}\right]+ & H_{T}\left[\frac{\partial \gamma}{\partial t}+\vec{v} \cdot \nabla \gamma\right] \\
& =\nabla \cdot\left[K_{b} \nabla p_{b}\right]+\nabla \cdot\left[H_{T} D_{H} \nabla \gamma\right]
\end{aligned}
$$

Applying the following chain rule, the above equation can be written as

$$
\begin{array}{r}
\frac{\partial \gamma}{\partial t}=\frac{\partial \gamma}{\partial p_{b}} \cdot \frac{\partial p_{b}}{\partial t}=\gamma^{\prime}(p) \frac{\partial p_{b}}{\partial t}, \nabla \gamma=\gamma^{\prime}(p) \nabla p \\
\alpha_{b}\left[\frac{\partial p_{b}}{\partial}+\vec{v} \cdot \nabla p_{b}\right]+H_{t}\left[\gamma(p) \frac{\partial p_{b}}{\partial t}+\vec{v} \cdot \gamma(p) \nabla p_{b}\right] \\
\left.=\nabla_{i} K_{b} \nabla p_{b}\right]+\nabla \cdot\left[H_{l} D_{H} \gamma^{\prime}(p) \nabla p_{b}\right]
\end{array}
$$

Simplification of the above equation gives

$$
\begin{aligned}
& \left.\alpha_{b}\left[1+\frac{H_{T}}{\alpha_{b}} \gamma(p)\right] \frac{\partial p_{b}}{\partial t}+\vec{v} \cdot \nabla p_{b}\right]=\nabla \cdot K_{b}\left[1+\frac{H_{T}}{K_{b}} D_{H} \gamma(p)\right] \nabla p_{b} \\
& \Rightarrow \alpha_{b}(1+m)\left[\frac{\partial p_{b}}{\partial t}+\vec{v} \cdot \nabla p_{b}\right]=\nabla \cdot K_{b}\left[1+\frac{H_{T}}{K_{b}} D_{H} \gamma(p)\right] \nabla p_{b}
\end{aligned}
$$

where $\mathrm{m}=\frac{\mathrm{H}_{\mathrm{T}}}{\alpha_{\mathrm{b}}} \gamma^{\prime}(\mathrm{p})$ and $\gamma^{\prime}(\mathrm{p})$ is the first derivative of $\gamma(\mathrm{p})=\frac{\left(\mathrm{p} / \mathrm{p}_{50}\right)^{n}}{1+\left(\mathrm{p} / \mathrm{p}_{50}\right)^{n}}$.

The term $\mathrm{K}_{\mathrm{b}}(1+\ldots)$ is referred to as effective conductivity $\mathrm{K}_{\text {eff. }}$. Hence, the oxygen transport equation for the blood region becomes

$$
\alpha_{b}(1+m)\left[\frac{\partial p_{b}}{\partial t}+\vec{v} \cdot \nabla p_{b}\right]=\nabla \cdot\left[K_{e f f} \nabla p_{b}\right]
$$

In cylindrical co-ordinates, the above equation can be written as, $\alpha_{b}(1+m)\left[\frac{\partial p_{b}}{\partial t}+v \frac{\partial p_{b}}{\partial z}\right]=K_{e f f}\left[\frac{1}{r} \frac{\partial}{\partial r}\left(r \frac{\partial p_{b}}{\partial r}\right)+\frac{\partial^{2} p_{b}}{\partial z^{2}}\right]$

Replacing $K_{\text {eff }}$ by $\alpha_{b} D_{b}$ and dividing by $\alpha_{b}$,

$(1+m)\left[\frac{\partial p_{b}}{\partial t}+v \frac{\partial p_{b}}{\partial z}\right]=D_{b}\left[\frac{1}{r} \frac{\partial}{\partial r}\left(r \frac{\partial p_{b}}{\partial r}\right)+\begin{array}{c}\partial^{2} p_{b} \\ \left(\frac{3 z^{2}}{\partial z}\right)\end{array}\right]$

For the tissue region, the $\mathrm{O}_{2}$ transport $\mathrm{eq}^{\mathrm{n}}$ can be written as

$\alpha_{t}\left[\frac{\partial p_{t}}{\partial t}\right]=K_{t}\left[\frac{1}{r} \frac{\partial}{\partial r}\left(r \frac{\partial p_{t}}{\partial r}\right)+\frac{\partial^{2} p_{t}}{\partial z^{2}}\right]-m_{0}$

where $\mathrm{m}_{0}$ is the volumetric metabolic oxygen consumption rate of tissue (assumed constant).

After dividing both sides by $\alpha_{\mathrm{b}}$

$\left(\frac{\alpha_{t}}{\alpha_{b}}\right)\left[\frac{\partial p_{t}}{\partial t}\right]=\left(\frac{\alpha_{t}}{\alpha_{b}}\right) D_{t}\left[\frac{1}{r} \frac{\partial}{\partial r}\left(r \frac{\partial p_{t}}{\partial r}\right)+\frac{\partial^{2} p_{t}}{\partial z^{2}}\right]-\left(\frac{m_{0}}{\alpha_{t}}\right)$

\section{Boundary Conditions}

The boundary conditions needed to solve equations 15 and 16 are as follows:

Blood region: $0 \leq z \leq L$ and $0 \leq r \leq r_{c}$

BC 1: $\mathrm{z}=0, \mathrm{p}_{\mathrm{b}}=\mathrm{p}_{\mathrm{b}}(\mathrm{t})$

BC 2: $\mathrm{z}=\mathrm{L}, \partial \mathrm{p}_{\mathrm{b}} / \partial \mathrm{z}=0$

BC 3: $\mathrm{r}=0, \partial \mathrm{p}_{\mathrm{b}} / \partial \mathrm{r}=0$

BC 4: $r=r_{c}, p_{b}=p_{t}$ and $D b \frac{\partial p_{b}}{\partial r}=\left(\frac{\alpha_{t}}{\alpha_{b}}\right) D_{t} \frac{\partial p_{t}}{\partial r}$

Tissue region: $0 \leq z \leq L$ and $r_{c} \leq r \leq r_{t}$

BC 5: $\mathrm{z}=0, \partial \mathrm{p}_{\mathrm{t}} / \partial \mathrm{z}=0$

BC 6: $\mathrm{z}=\mathrm{L}, \partial \mathrm{p}_{\mathrm{t}} / \partial \mathrm{z}=0$

BC 7: $r=r_{t}, \partial p_{t} / \partial z=0$

These two boundary conditions state that oxygen cannot leave the tissue region at either end by axial diffusion.

\section{Analytical Solution}

Solution of the above equations for the oxygen concentrations within the blood and tissue regions is a formidable problem which can be accomplished numerically with the help of computational techniques but, a reasonable analytical solution can be obtained with some simplifications and this was explored by Fournier ${ }^{6}$.

The basic assumptions include, 1) steady-state condition, 2) $\mathrm{m}$ is constant, 3) negligible axial diffusion within the tissue region, 4) within the 
capillary, negligible axial diffusion in comparison to axial convection.

Applying these assumptions in equation 15 gives

$$
(1+m) v \frac{\partial p_{b}}{\partial z}=D_{b}\left(\frac{1}{r} \frac{\partial}{\partial r}\left(r \frac{\partial p_{b}}{\partial r}\right)\right)
$$

Radial averaging of the above equation gives

$$
\begin{aligned}
& 2 \pi \int_{0}^{r_{c}}(1+m) v \frac{\partial p_{b}}{\partial z} r d r=2 \pi D_{b} \int_{0}^{r_{c}} \frac{1}{r}\left(\frac{\partial}{\partial r}\left(r \frac{\partial p_{b}}{\partial r}\right)\right) r d r \\
& \Rightarrow 2 \pi(1+m) v \frac{d}{d z} \int_{0}^{r_{c}} p_{b} r d r=\left.2 \pi D_{b} r_{c} \frac{\partial p_{b}}{\partial r}\right|_{r_{c}}
\end{aligned}
$$

The radially averaged $\mathrm{pO}_{2}$ level in the blood, $\left\langle p_{b}\right\rangle$ can be defined as

$$
\left\langle p_{b}\right\rangle \pi r_{c}^{2}=2 \pi \int_{0}^{r_{c}} p_{b} r d r
$$

This allows equation 22 to be written as

$$
(1+m) \frac{\partial\left\langle p_{b}\right\rangle}{\partial z}=\left.\frac{2 D_{b}}{r_{c} v} \frac{d p_{b}}{d r}\right|_{r_{c}}
$$

Applying BC 4 in the above equation, we have

$$
(1+m) \frac{\partial\left\langle p_{b}\right\rangle}{\partial z}=\left.\frac{2 D_{t} \alpha_{t}}{r_{c} v \alpha_{b}} \frac{d p_{t}}{d r}\right|_{r_{c}}
$$

The basic assumptions simplifies equation 17 to the following form

$$
\frac{d}{d r}\left(r \frac{d p_{t}}{d r}\right)=\frac{m_{0}}{\alpha_{t} D_{t}} r
$$

Integration of the above equation two times followed by application of the boundary conditions 4 and 7 in equations 18 and 19 gives the following result.

$$
p_{t}(r, z)=\left\langle p_{b}(z)\right\rangle-\frac{r_{c}^{2} m_{0}}{4 \alpha_{t} D_{t}}\left[1-\left(\frac{r}{r_{c}}\right)^{2}\right]-\frac{r_{t}^{2}}{2 \alpha_{t} D_{t}} \ln \left(\frac{r}{r_{c}}\right)
$$

Equation 27 is the analytical solution of the oxygen concentration equation in the tissue region.

Differentiation of Equation 27 with respect to $r$ at $r=r_{c}$ gives the following equation

$$
\left.\frac{d p_{t}}{d r}\right|_{r_{c}}=\frac{r_{c} m_{0}}{2 \alpha_{t} D_{t}}-\frac{r_{t}{ }^{2} m_{0}}{2 \alpha_{t} D_{t} r_{c}}
$$

Using this result in equation 26 gives

$$
(1+m) \frac{\partial\left\langle p_{b}\right\rangle}{\partial z}=\frac{2 D_{t} \alpha_{t}}{r_{c} v \alpha_{b}}\left(\frac{r_{c} m_{0}}{2 \alpha_{t} D_{t}}-\frac{r_{t}^{2} m_{0}}{2 \alpha_{t} D_{t} r_{c}}\right)
$$

$\Rightarrow \frac{d\left\langle p_{b}\right\rangle}{d z}=-\frac{m_{0}}{(1+m)\left(\alpha_{b} v\right)}\left[\left(\frac{r_{t}}{r_{c}}\right)^{2}-1\right]$

This equation may be integrated to give the following result,

$$
\left\langle p_{b}(z)\right\rangle=\left\langle p_{b}\right\rangle_{\text {in }}-\frac{m_{0}}{(1+m)\left(\alpha_{b} v\right)}\left[\left(\frac{r_{t}}{r_{c}}\right)^{2}-1\right] z
$$

Equation 31 is the analytical solution of the oxygen concentration equation in the capillary region.

\section{Results and Analyses}

The results obtained by using CFD software CFX 4.4 for the numerical solution of the Kroghian model have been compared with the results of the aforementioned analytical solutions in a view to justify the use of CFX 4.4 for developing more realistic mathematical model of bone marrow ${ }^{7}$.

Figure 3 depicts the comparison between analytical and numerical solution for the tissue region at an input oxygen partial pressure of $80 \mathrm{~mm} \mathrm{Hg}$ and a radial distance of $160 \mu \mathrm{m}$ in the capillary region. It clearly demonstrates that the oxygen partial pressure gradually decreases with the increase of radial distance in the tissue region, which signifies that the oxygen concentration distant from the supplying region experiences lower oxygen content. This in turn can affect the cellular functions residing in this region, such as granulopoietic cells. The small variation in the partial pressure of oxygen is due to the choice of the lowest consumption rate for the cells (granulocytes).

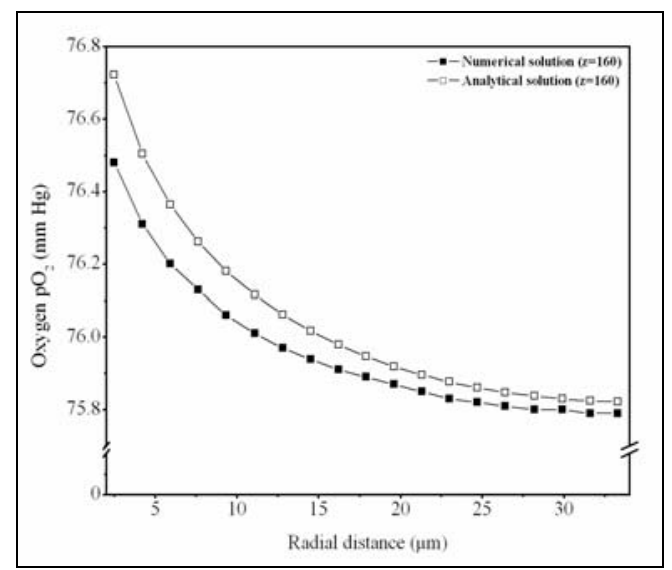

Fig 3. Plot of numerical vs. analytical solution for tissue region at $\mathrm{pO}_{2}=80 \mathrm{~mm} \mathrm{Hg}$ and $\mathrm{Z}=160$ $\mu \mathrm{m}$. 


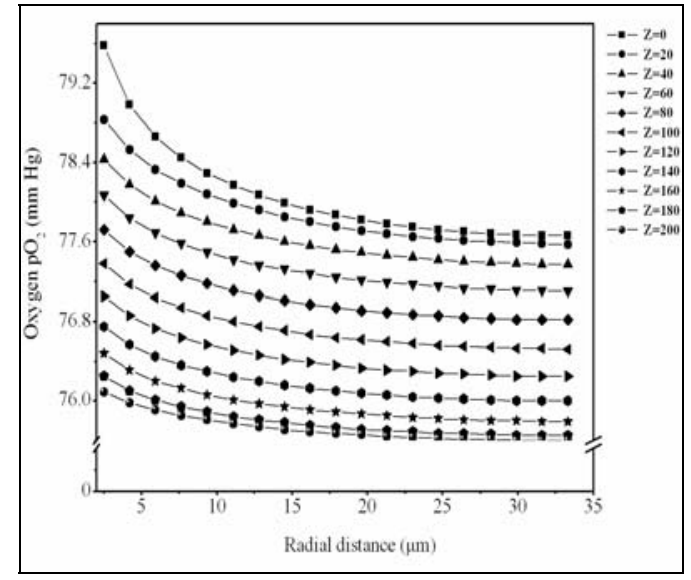

Fig 4. Plot of numerical solutions in different capillary distances for the tissue region at $\mathrm{pO}_{2}=80 \mathrm{~mm} \mathrm{Hg}$.

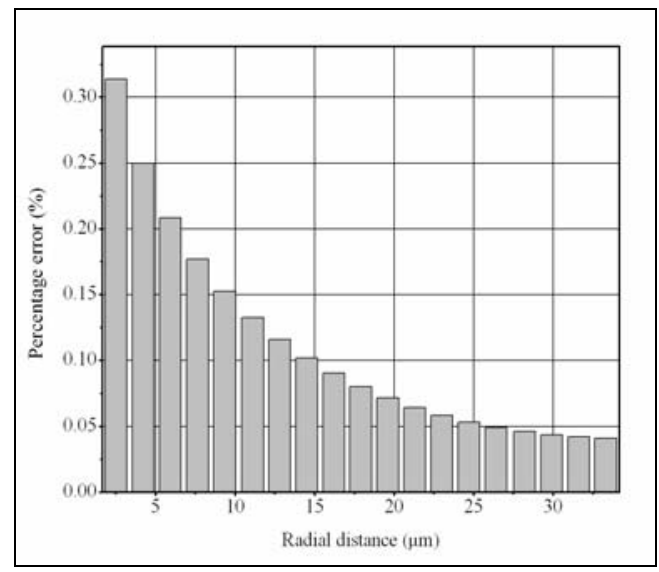

Fig 5. Percentage error in between numerical and analytical solution for the tissue region at $\mathrm{pO}_{2}=\mathbf{8 0}$ mm Hg.

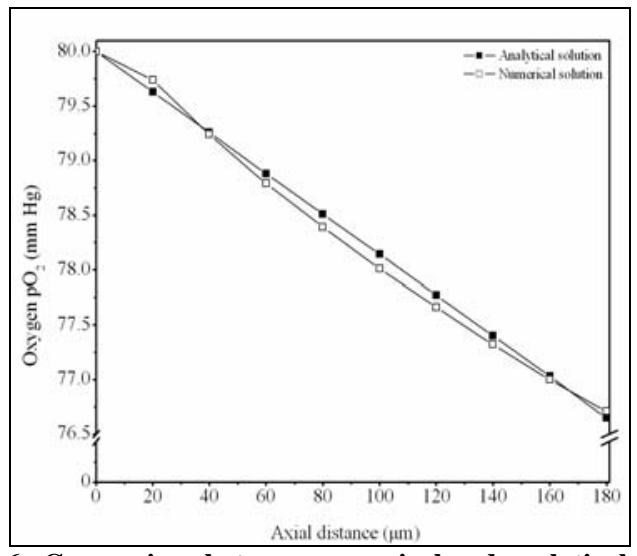

Fig 6. Comparison between numerical and analytical solution for the capillary region at $\mathrm{pO}_{2}=80 \mathrm{~mm}$

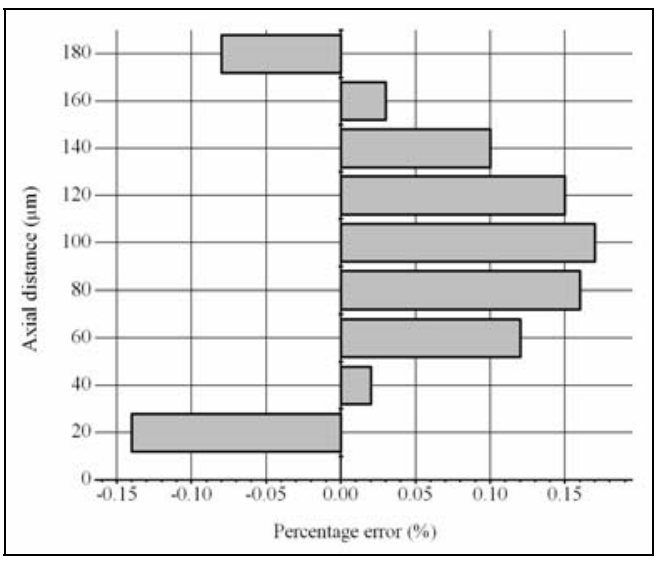

Fig 7. Percentage error between numerical and analytical solution for the capillary region at $\mathrm{pO}_{2}$ $=80 \mathrm{~mm}$ Hg.

Figure 4 illustrates the varying oxygen tension with radial distance in the $\mathrm{BM}$ microenvironment, at different axial distances in the capillary region. The main objective of this section is to high-light the minimal error between the numerical solutions obtained from CFX when compared to an analytical solution, and in Figure 5 the error between analytical and numerical solution is between (0.05-0.35) \%; which is within the acceptable margin of error $(1 \%)$. Furthermore, the error decreases exponentially as the radial distance increases.

Figure 6 is the comparison of analytical and numerical solutions for the capillary region, while Figure 7 is the error of the solutions for the capillary. The only notable difference from the solutions for the tissue region is that for capillary, the trend of decreasing oxygen partial pressure is linear which demonstrates the homogeneity of the capillary region. Hence, the error is also much lower than the capillary region and in some instances the error almost diminishes.

\section{Conclusion}

Given the small error between the expected and the simulated data, the numerical method utilized within this work is assumed to be predictive, with a high level of confidence. This in turn validates the use of CFX 4.4 to develop more realistic mathematical models for normal as well as pathological BM with potential clinical applications.

\section{Acknowledgement}

The author is indebted to commonwealth scholarship commission, UK for funding this project. 


\begin{tabular}{|c|c|c|}
\hline \multicolumn{3}{|c|}{ Nomenclature } \\
\hline $\mathrm{D}_{\mathrm{b}}$ & $\begin{array}{l}\text { Diffusion coefficient of } \\
\text { blood in tissue }\end{array}$ & $\mathrm{cm}^{2} \mathrm{~s}^{-1}$ \\
\hline $\mathrm{D}_{\mathrm{t}}$ & $\begin{array}{l}\text { Diffusion coefficient of } \\
\text { oxygen in tissue }\end{array}$ & $\mathrm{cm}^{2} \mathrm{~s}^{-1}$ \\
\hline $\mathrm{H}_{\mathrm{T}}$ & $\begin{array}{l}\text { Volume fraction of } \\
\text { hemoglobin in blood }\end{array}$ & $\%$ \\
\hline M & $\begin{array}{l}\text { Modified Hill Constant } \\
\text { for } \mathrm{CO}_{2}\end{array}$ & $1 / \mathrm{mmHg}$ \\
\hline $\mathrm{m}_{0}$ & $\begin{array}{l}\text { Volumetric oxygen } \\
\text { consumption rate }\end{array}$ & $\mathrm{mol} \mathrm{O}_{2} \mathrm{~cm}^{-3} \mathrm{~s}^{-1}$ \\
\hline $\mathrm{K}_{\mathrm{eff}}$ & $\begin{array}{l}\text { Effective Krogh } \\
\text { coefficient }\end{array}$ & $\begin{array}{l}\mathrm{mol} \mathrm{O}_{2} \mathrm{~cm}^{3} \mathrm{~s}^{-1} \\
\mathrm{mmHg}^{-1}\end{array}$ \\
\hline $\mathrm{K}$ & Oxygen permeability & $\begin{array}{l}\mathrm{mol} \mathrm{O}_{2} \mathrm{~cm}^{-3} \mathrm{~s}^{-1} \\
\mathrm{mmHg}^{-1}\end{array}$ \\
\hline $\mathrm{K}_{\mathrm{b}}$ & $\begin{array}{l}\text { Oxygen permeability- } \\
\text { blood }\end{array}$ & $\begin{array}{l}\mathrm{mol} \mathrm{O}_{2} \mathrm{~cm}^{-3} \mathrm{~s}^{-1} \\
\mathrm{mmHg}^{-1}\end{array}$ \\
\hline $\mathrm{K}_{\mathrm{t}}$ & $\begin{array}{l}\text { Oxygen permeability- } \\
\text { tissue }\end{array}$ & $\begin{array}{l}\mathrm{mol} \mathrm{O}_{2} \mathrm{~cm}^{-3} \mathrm{~s}^{-1} \\
\mathrm{mmHg}^{-1}\end{array}$ \\
\hline $\mathrm{pO}_{2}$ & $\begin{array}{l}\text { Oxygen tension (Partial } \\
\text { pressure) }\end{array}$ & $\mathrm{mm} \mathrm{Hg}$ \\
\hline $\mathrm{p}_{\mathrm{t}}$ & $\begin{array}{l}\text { Oxygen Tension in } \\
\text { tissue }\end{array}$ & $\mathrm{mm} \mathrm{Hg}$ \\
\hline $\mathrm{p}_{\mathrm{b}}$ & $\begin{array}{l}\text { Oxygen Tension in } \\
\text { blood }\end{array}$ & $\mathrm{mm} \mathrm{Hg}$ \\
\hline $\mathrm{r}_{\mathrm{t}}$ & $\begin{array}{l}\text { Radius of the tissue } \\
\text { cylinder }\end{array}$ & $\mu \mathrm{m}$ \\
\hline $\mathrm{r}_{\mathrm{c}}$ & Radius of the sinus & $\mu \mathrm{m}$ \\
\hline
\end{tabular}

\section{Greek Symbols}

$\begin{array}{ll}\alpha_{b} & \text { Oxygen solubility-blood } \\ \alpha_{t} & \text { Oxygen solubility-tissue } \\ \gamma & \begin{array}{l}\text { Oxygen saturation } \\ \text { function }\end{array}\end{array}$

\section{References}

1. Groebe, K. and Thews, G., Basic mechanisms of diffusive and diffusion-related oxygen transport in biological systems: a review. Adv Exp Med Biol . 317(Oxygen Transport to Tissue XIV): 21-33, 1992.

2. Kreuzer, F., Oxygen supply to tissue: the Krogh model and its assumptions, Experientia, 38: 14151426, 1982.

3. Ellsworth, M.L. and Pitman, R.N., Arterioles supply oxygen to capillaries by diffusion as well as by convection, Am J Physiol, 258: H1240H1243, 1990.

4. Popel, A.S., Theory of Oxygen Transport to Tissue, Critical Reviews in Biomedical Engineering, 17(3): 257-321, 1989.

5. Reneau, D.D. Jr, Bruley, D.F. and Kinsley, M.H., A mathematical simulation of oxygen release, diffusion, and consumption in capillaries and tissue of the human brain, Chemical Engineering in Medicine and Biology, Hershey, D. (ed.) (Plenum Press, New York, USA), pp 135, 1967.

6. Fournier, R.L., Basic Transport Phenomena in Biomedical Engineering, Crc Press Llc; 1 edition, 1998.

7. Islam, M.A., Simulating Oxygen Transport in the Human Bone Marrow: Hemolytic Sickle Cell Anemia Study, MSc Thesis, Imperial College London, 2005. 